\title{
Overexpression of PTPN2 in Visceral Adipose Tissue Ameliorated Atherosclerosis via T Cells Polarization Shift in Diabetic Apoe ${ }^{-/-}$Mice
}

\author{
Ya Lia Huimin Zhou Feng Wang ${ }^{a}$ Lu Han a,b Minghao Liu ${ }^{a}$ Yihui Lia \\ Zhihao Wang ${ }^{\mathrm{a}, \mathrm{c}}$ Mengxiong Tanga,d Wei Zhang ${ }^{\mathrm{a}} \quad$ Ming Zhong $^{\mathrm{a}}$ \\ aThe Key Laboratory of Cardiovascular Remodeling and Function Research, Chinese Ministry of \\ Education and Chinese Ministry of Health, and The State and Shandong Province Joint Key Laboratory \\ of Translational Cardiovascular Medicine, Department of Cardiology, Qilu Hospital of Shandong \\ University, Jinan, Shandong, 'Department of General Practice, Qilu Hospital of Shandong University, \\ Jinan, Shandong, 'Department of Geriatric Medicines, Qilu Hospital of Shandong University, Jinan, \\ Shandong, 'Department of Emergency, Qilu Hospital of Shandong University, Jinan, Shandong, China
}

\section{Key Words}

Ptpn2 • Adipose tissue $\cdot$ T cells polarization • Systemic inflammation • Atherosclerosis

\begin{abstract}
Background/Aims: Dysregulated inflammation in adipose tissue, marked by increased pro-inflammatory T-cell accumulation and reduced regulatory $\mathrm{T}$ cells (Treg), contributes to diabetes-associated insulin resistance and atherosclerosis. However, the molecular mechanisms underlying T-cell-mediated inflammation in adipose tissue remain largely unknown. Methods: Sixty apolipoprotein E $\left(\mathrm{ApoE}^{-1}\right)$ mice were randomly divided into chow and diabetes groups. Diabetes was induced by a high-fat and high-sugar diet combined with low-dose streptozotocin. Then we transferred a recombinant adenovirus carrying the protein tyrosine phosphatase non-receptor type 2 (PTPN2) gene into epididymal white adipose tissue (EWAT) of $\mathrm{ApoE}^{-/-}$mice. After transfection, all mice were euthanized to evaluate the effects of PTPN2 on T cells polarization and atherosclerosis. Results: PTPN2 was downregulated in EWAT of diabetic ApoE ${ }^{-/}$mice. PTPN2 overexpression in EWAT reversed the high Th1/Treg and Th17/Treg ratios in EWAT of diabetic mice. In addition, PTPN2 overexpression in EWAT could significantly reduce macrophages infiltration, the ratio of $\mathrm{M} 1 / \mathrm{M} 2$ macrophages and the expression of pro-inflammatory cytokines in EWAT, improving insulin resistance. In aortic root lesions, the vulnerability index were significantly decreased by overexpression of PTPN2 in EWAT. Conclusion: These data suggested that PTPN2 overexpression in EWAT would inhibit systemic inflammation and increase the plaque stability via T cells polarization shift in diabetic mice.




\section{Cellular Physiology \begin{tabular}{l|l} 
and Biochemistry Published online: March 26, 2018 & $\begin{array}{l}\text { (C) } 2018 \text { The Author(s). Published by S. Karger AG, Basel } \\
\text { www.karger.com/cpb }\end{array}$
\end{tabular} \\ Li et al.: PTPN2 Overexpression in Visceral Adipose Tissue Ameliorated Atherosclerosis}

\section{Introduction}

The increased prevalence of type 2 diabetes mellitus (T2DM) has focused attention on the elevated incidence of diabetic atherosclerosis [1]. Chronic systemic inflammation is assumed to be a common soil for the development of both T2DM and atherosclerosis $[2,3]$. Adipose tissue, as the major contributor for chronic systemic inflammation, played a vital role in diabetic atherosclerosis [4]. Given its greater capacity for the production and secretion of pro-inflammatory cytokines, visceral adipose tissue (VAT), notably the epididymal white adipose tissue (EWAT) depot in mice and omental depot in humans, has been demonstrated to be more closely associated with atherosclerosis compared with subcutaneous depot [5]. Inflamed VAT can promote atherogenesis by driving systemic inflammation [6]. Therefore, the underlying modulator of VAT inflammation might be explored as part of the approach to reduce the burden of atherosclerotic diseases in T2DM.

VAT inflammation is closely associated with immune dysfunction in diabetes [7]. At the cellular level, immune cells including T cells, B cells, and macrophages were involved in adipose tissue inflammation [8-10]. Our previous study has shown that macrophage infiltration and polarization were of critical importance in adipose tissue inflammation and the development of insulin resistance [11]. In addition, adipose tissue macrophages (ATMs) polarization is assumed to be associated with coronary atherosclerosis [12]. However, ATMs polarization may not be the initiator of inflammatory responses in adipose tissue $[13,14]$. Accumulating evidence implicates T cells are important modulators of ATMs polarization and play an important role in the initiation and perpetuation of adipose tissue inflammation $[13,15,16]$. Pro-inflammatory T-helper 1 (Th1) and T-helper 17 (Th17) lymphocytes infiltrate VAT, where they overcome the anti-inflammatory effects of T-regulatory (Treg) cells, promoting classical activation of macrophages and systemic insulin resistance or glucose intolerance $[14,17-22]$. The key signaling mediators that regulate $\mathrm{T}$ cells polarization during diabetes, however, are largely unexplored.

Protein tyrosine phosphatase non-receptor type 2 (PTPN2, gene ID: 19255) might be the key regulator that controls the T cells polarization [22,23]. PTPN2, one of 17 intracellular and non-receptor PTPs, was originally cloned from a human T-cell cDNA library [24]. It is ubiquitously expressed (e.g., intestinal and renal epithelium, fibroblasts, hepatocytes), but an extraordinary high expression is observed in lymphoid cells, including T cells [25]. Loss of PTPN2 in the T cell compartment causes enhanced induction of Th1 and Th17 cells, but impaired induction of Treg in several mouse colitis models [22]. However, the role of PTPN2 in adipose tissue T cells polarization remains unknown. In particular, it has been documented that PTPN2 negatively regulates the STAT3 activity either in the cytoplasm, through dephosphorylating protein tyrosine kinase JAK, or in the nucleus, through directly dephosphorylating STAT3 [26, 27]. Functional ablation of Stat3 in T cells reverses the high Th1/Treg ratio in VAT of diet-induced obesity mice [15]. Thus, PTPN2 might modulate T cells polarization via STAT3 signaling pathway, ameliorating VAT inflammation and diabetesrelated atherosclerosis.

In the present study, we constructed a type 2 diabetic atherosclerosis $\mathrm{ApoE}^{-/}$mouse model as previously [28]. Then we transfered adenovirus-PTPN2 (Ad-PTPN2) into EWAT (the largest and easily harvested VAT depot in mice [29]) of type 2 diabetic ApoE1- mouse, and evaluated whether PTPN2 overexpression in EWAT could alleviate diabetic atherosclerosis via $\mathrm{T}$ cells polarization shift and corresponding reduction of local and chronic systemic inflammation. The signaling pathway mechanism underlying adipose tissue T cells polarization was also explored.

\section{Materials and Methods}

Induction of diabetes and atherosclerosis in mice

This study enrolled 60 male ApoE-/- mice at 4 weeks (body weight 12-16 g, experimental animal center of Shandong University of Traditional Chinese Medicine, Ji'nan, China). All experimental procedures were 


\section{Cellular Physiology Cell Physiol Biochem 2018;46:118-132 \begin{tabular}{l|l} 
DOI: 10.1159/000488415 & Ond Biochemistry 2018 The Author(s). Published by S. Karger AG, Basel \\
wwww.karger.com/cpb
\end{tabular}

performed in accordance with the animal protocols approved by the Shandong University Animal Care Committee. The animals were maintained under standard laboratory conditions $\left(25^{\circ} \mathrm{C}\right.$ temperature, 60 $70 \%$ relative humidity, and 12-h light-dark cycles). The animals were allowed to acclimate for 1 week before performing intraperitoneal glucose tolerance test (IPGTT). All mice were randomly assigned to a control group ( $\mathrm{N}$ group, $\mathrm{n}=30$ ) and diabetic group (DM group, $\mathrm{n}=30$ ). The control group received normal chow; the diabetic groups were fed a high-fat (HF) diet (34.5\% fat, $17.5 \%$ protein, and $48 \%$ carbohydrate; Beijing HFK Bio-Technology, China). After 8 weeks, IPGTT was performed to confirm the appearance of insulin resistance. The control group received citrate buffer (intraperitoneally) alone. Those mice showing insulin resistance were injected once with low dose of streptozotocin (STZ) (Sigma, St. Louis, M0; 75-80 $\mathrm{mg} / \mathrm{kg}$ i.p. in $0.1 \mathrm{~mol} / \mathrm{L}$ citrate buffer, $\mathrm{pH} 4.5$ ) intraperitoneally. Two weeks after the STZ injection, most high-fat diet/STZ-treated mice displayed hyperglycemia, insulin resistance, and glucose intolerance, as previously reported [30]. At age 14 weeks, mice with similar degrees of hyperglycemia and body weight were randomly divided into vehicle (DM+Vehicle, $n=15)$ and PTPN2-overexpression (DM+PTPN2, n=15) groups. The mice fed a normal diet were used as non-diabetic controls, divided into $\mathrm{N}+$ Vehicle $(\mathrm{n}=15)$ and PTPN2 overexpression (N+PTPN2, n=15) groups.

\section{Intraperitoneal glucose tolerance test (IPGTT)}

Glucose tolerance was assessed by IPGTT after mice fasted for $12-16 \mathrm{~h}$. A bolus of glucose $(2 \mathrm{~g} / \mathrm{kg})$ was injected intraperitoneally, and blood samples were collected from the tail vein at 0, 15, 30,60 and 120 min and glucose was measured using a OneTouch Glucometer (LifeScan, Milpitas, CA). The mean area under the receiver operating characteristic curve (AUC) was calculated for glucose.

\section{Production and administration of adenoviral vector}

The recombinant pAdxsi adenovirus constitutively expressing PTPN2 was constructed using the pAdxsi Adenoviral System (SinoGenoMax, Beijing, China). The PTPN2 cDNAs from mouse were inserted into pShuttle-CMV-EGFP vector. The pAdxsi vector adenovirus was used as the control vehicle virus. Mice were treated with $5 \times 10^{9}$ plaque-forming units of virus by subcutaneous injection into the EWAT at 20 weeks [31]. Adenovirus transfer was repeated at 22 weeks. The control group was injected with control virus (vehicle). Four weeks after first adenovirus injection, all mice were euthanized for further study.

\section{Blood examination}

At the end of experiment, the mice were fasted overnight and euthanized by an over dose of pentobarbital. Serum levels of Aspatate transminase (ALT) and alanine transminase (AST) were measured using commercial assay kits (Pointe Scientific, Lincoln Park, MI).

\section{Histological and morphometric analyses}

Samples were taken from EWAT. Each adipose tissue sample was cut into 2 pieces. One-half of the samples were fixed in paraformaldehyde (4\%) and embedded in paraffin, and cut into $5 \mu \mathrm{m}$ sections. A single adipocyte was measured with images captured from hematoxylin and eosin (HE) stained sections. Every adipocyte area was assessed under $\times 400$ magnification within adipose tissue, and a mean was obtained by quantitative morphometry with automated image analysis (Image-Pro Plus, Version 5.0; Media Cybernatics, Houston, TX). Liver tissues fixed in paraformaldehyde (4\%) and embedded in paraffin, and cut into $5 \mu \mathrm{m}$ sections. Ten fields were randomly selected and vacuolized hepatic cells were counted manually using the Image J plugins cell count. The percentage of vacuolized hepatic cells was calculated to quantify liver pathological alternation.

\section{Immunohistochemical staining}

Paraffin sections underwent immunohistochemistry by a microwave-based antigen retrieval method. The sections were incubated with primary rabbit polyclonal anti-PTPN2 (Abcam, Cambridge, MA, USA), antiP-STAT3 (Cell Signaling Technology, Beverly, MA), anti-FASN (Santa Cruz, CA, USA), anti-HSL (Santa Cruz, CA, USA), anti-Perilipin (Santa Cruz, CA, USA), anti-ATGL (Santa Cruz, CA, USA), anti-CD11c (Abcam, Cambridge, MA, USA), anti-CD206 (Abcam, Cambridge, MA, USA), anti-IL-6 (Abcam, Cambridge, MA, USA), anti-TNF$\alpha(A b c a m$, Cambridge, MA, USA), anti-MCP-1 (Cell Signaling Technology, Beverly, MA), anti-IL-10 (Abcam, Cambridge, MA, USA) and primary rat polyclonal antiF4/80 antibodies (Abcam, Cambridge, MA, USA) 


\section{Cellular Physiology Cell Physiol Biochem 2018;46:118-132 \begin{tabular}{c|c|c|} 
DOI: 10.1159/000488415 & O 2018 The Author(s). Published by S. Karger AG, Basel \\
www.karger.com/cpb
\end{tabular} \\ Li et al.: PTPN2 Overexpression in Visceral Adipose Tissue Ameliorated Atherosclerosis}

overnight and then with a matching biotinylated secondary antibody for $30 \mathrm{~min}$ at $37^{\circ} \mathrm{C}$. Negative controls were omission of the primary antibody. The stained sections were developed with diaminobenzidine and counterstained with hematoxylin. The results were viewed under a confocal FV 1000 SPD laser scanning microscope (Olympus, Japan). The integrated optical density (IOD)/Total IOD (representive collagen content) were analyzed by quantitative morphometry with automated image analysis (Image-Pro Plus, Version 5.0; Media Cybernatics, Houston, TX).

For en face analysis, the aorta was opened longitudinally, stained with Sudan IV and quantified for lipid deposition. To analyze plaque area and composition, aortic root was embedded in optimal cutting temperature medium (Sakura Finetek, Flemingweg, Netherlands) and cryosectioned. Atherosclerotic lesion area $\left(\mathrm{mm}^{2}\right)$ and neutral lipid content were quantified in $8 \mu \mathrm{m}$ crosssections (covering $\approx 1,000 \mu \mathrm{m}$ from valve leaflets) after Oil-red-0/hematoxylin staining and averages were calculated from 3-5 sections. Parallel sections were analyzed for collagen content (picrosirius red staining). Corresponding sections were incubated with the primary antibodies against MOMA-2 (Abcam, Cambridge, MA, USA), $\alpha$-SMA (Abcam, Cambridge, MA, USA), MCP-1 (Cell Signaling Technology, Beverly, MA), TNF- $\alpha$ (Abcam, Cambridge, MA, USA), IL-6 (Abcam, Cambridge, MA, USA) and ICAM-1 (Abcam, Cambridge, MA, USA). The results were viewed under a confocal FV 1000 SPD laser scanning microscope (Olympus, Japan). Positive staining areas were analysed by computer-assisted colourgated measurement, and the en face and cross-sectional aortic plaque area was measured by Image-Pro Plus 6.0 analysis system and the vulnerability index was calculated as: (lipids staining \% + MOMA-2 staining \%)/ ( $\alpha$-SMA staining $\%+$ collagen staining \%) [32].

\section{Flow cytometry}

Adipose tissue (carefully avoiding lymph nodes) was dissected into 1 - to $5-\mathrm{mm}^{3}$ fragments, centrifuged to remove circulating cells, and digested with collagenase type D (2 mg/mL; Roche) and DNase I (1 mg/ $\mathrm{mL}$; Roche) for $30-45 \mathrm{~min}$ at $37^{\circ} \mathrm{C}$. Digests were filtered through $70-\mu \mathrm{m}$ cell strainers and pelleted to enrich for immune cells in stromal vascular fractions. After red blood cell (RBC) lysis (Sigma-Aldrich), single-cell suspensions were resuspended in FACS wash buffer (2\% FBS in HBSS without magnesium, calcium, and phenol red). Cells were blocked with CD16/32 and then incubated for 30 minutes on ice with fluorophoreconjugated antibody (CD4 from BD Biosciences).

For intracellular staining, cells were fixed and permeabilized using the Foxp3 Fixation/Permeabilization Kit (eBioscience) according to the manufacturer's protocol. After two washes, cells were stained for $30 \mathrm{~min}$ on ice with fluorophore-conjugated antibodies (IFN- $\gamma$, IL-17, and Foxp3, from BD Biosciences). Cells were washed twice before analysis on a BD LSRFortessa flow cytometer. Data were analyzed with FlowJo software (TreeStar).

\section{Western Blot}

Western blot analysis was as previously described [33]. We used antibodies against PTPN2 (Abcam, Cambridge, MA, USA), P-STAT3(Cell Signaling Technology, Beverly, MA), STAT3 (Cell Signaling Technology, Beverly, MA), Arg I (Abcam, Cambridge, MA, USA), Arg II (Abcam, Cambridge, MA, USA), MCP-1 (Cell Signaling Technology, Beverly, MA), TNF- $\alpha$ (Abcam, Cambridge, MA, USA), IL-6 (Abcam, Cambridge, MA, USA), IL-10 (Abcam, Cambridge, MA, USA), ICAM-1 (Abcam, Cambridge, MA, USA) and GAPDH (Abcam, Cambridge, MA, USA), followed by anti-IgG horseradish peroxidase-conjugated secondary antibody. PTPN2, Arg I, Arg II, MCP-1, TNF- $\alpha$, IL-6, IL-10 and ICAM-1 protein levels were normalized to that of GAPDH as an internal control and phosphorylated proteins to that of total protein.

\section{ELISA}

Plasma levels of IL-6, IFN- $\gamma$, TNF- $\alpha$, MCP- 1 and C-Reactive protein (CRP) was measured by use of ELISA kits (R\&D Systems).

\section{Statistical analysis}

Values are presented as mean \pm SEM. SPSS 17.0 (SPSS, Chicago, IL) was used for statistical analysis. Results were compared by one-way ANOVA, followed by Tukey-Kramer post hoc test and independent samples $t$ test. A $P<0.05$ was considered statistically significant.

\section{KARGER}




\section{Results}

Generation of diabetic atherosclerosis mouse model

Diabetic atherosclerosis is induced in $\mathrm{ApoE}^{-/}$mice. We generated a non-genetic rodent model closely resembling human diabetic atherosclerosis disease by feeding male ApoE $\mathrm{E}^{-/}$mice with high-fat (HF) diet and by the STZ treatment (referred to as DM mice hereafter), and normal diet (chow diet) fed mice serve as controls, as previously reported [30].

Insulin resistance in the DM mice was confirmed by IPGTT. The levels of blood glucose in the DM group were similar to that of the control group at the age of 4 weeks $(P>0.05)$ (Fig. $1 \mathrm{~B}$ and $\mathrm{E}$ ). However, at the age of 12 and 14 weeks, the levels of blood glucose in the DM group were significantly higher than the control mice at all of the time points tested $(P<0.05)$ (Fig. $1 \mathrm{C}$ and D). Similarly, at the age of 12 and 14 weeks, the AUC for glucose level of the DM mice was higher compared with the control mice compared to that at baseline of 3 weeks $(P<0.05)$ (Fig. $1 \mathrm{~F}$ and G). Intraperitoneal glucose tolerance test results in the control mice had no significant changes between week-4 and week-14.

As expected, the bodyweight was significantly higher in the DM group than in the control group at and after week-12 except at week-14 $(P<0.05)$ (Fig. 1A).

We subsequently evaluated hepatic function. Hepatomegaly in diabetic mice, as indicated by incre

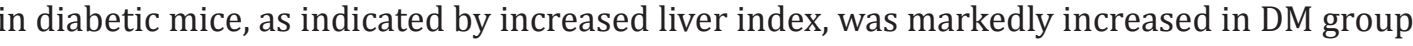
$(P<0.05)$ (Fig. 2A). Elevated serum levels of ALT and AST were significantly increased in diabetic mice $(P<0.05)$ (Fig. 2B). Meanwhile, hepatic vacuolization and necrosis was induced by diabetes, as was demonstrated by pathological examination $(P<0.05)$ (Fig. $2 \mathrm{C})$.

We also confirmed atherosclerosis as previously [30] reported in the DM mice at the age of 24 weeks after high fat diet and STZ treatment $(P<0.05)$ (Fig. 9A and C).

In summary, the diabetic model induced by a HF diet and STZ showed typical features of insulin resistance, hyperglycaemia, obesity and aorta lipid accumulation, resembling the state of human diabetic atherosclerosis disease. 
Morphological and functional remodeling of EWAT in diabetic mice

Our analysis revealed significant increase in EWAT mass in the diabetic group compared with the normal group $(P<0.05)$ (Fig. $3 A)$. In addition, adipocyte cell diameter, determined by quantification of HE staining in EWAT, was larger in the diabetic group compared with the normal group $(P<0.05)$ (Fig. 3B).

To evaluate the impact of diabetes on EWAT metabolism, we assessed protein levels of various markers of fatty acid metabolism by immunochemistry. We found decreased expression of adipose triglyceride lipase (ATGL), hormone sensitive lipase (HSL), and Perilipin in EWAT of diabetic mice compared with normal mice $(P<0.05)$ (Fig. 3C). We also detected increased expression of fatty acid synthase (FASN) $(P<0.05)$ (Fig. 3C) in EWAT of diabetic mice compared with normal mice. Taken together, these data indicated diabetes induced morphological and functional remodeling of EWAT.

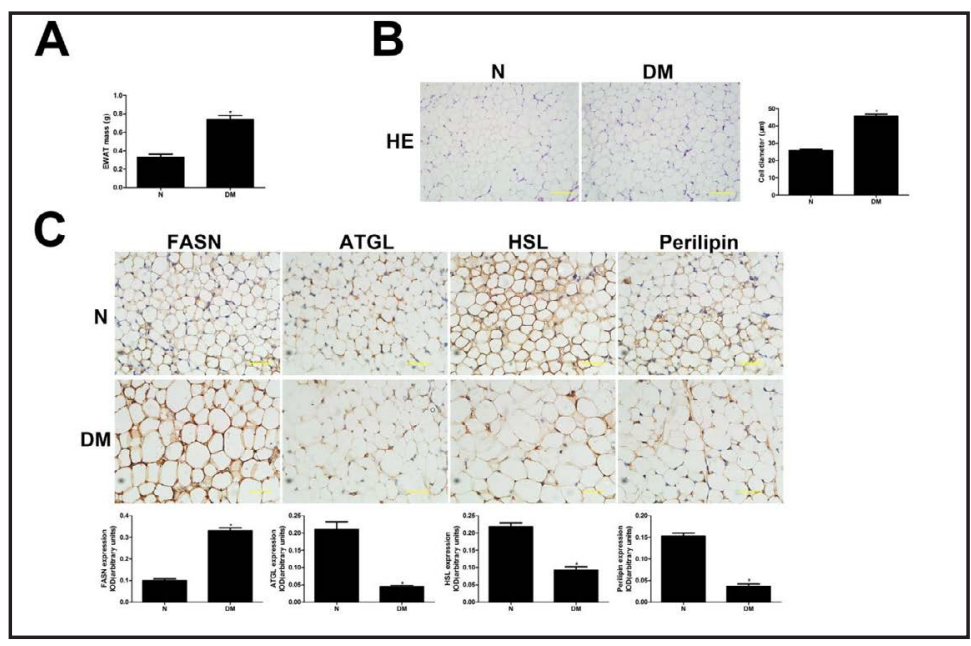

Fig. 3. Morphological and functional remodeling of EWAT in diabetic mice. (A) The weight of EWAT. (B) EWAT stained with HE (Scale bars: $50 \mu \mathrm{m})$. (C) Immunohistochemical staining for FASN, ATGL, HSL and Perilipin in EWAT (brown staining considered positive staining; scale bar: $50 \mu \mathrm{m}$ ). Data are mean \pm SEM ( $\mathrm{n}=7-8$ per group). ${ }^{*} \mathrm{P}<0.05$ verus $\mathrm{N}$. IOD: integrated optical density; EWAT: epididymal white adipose tissue; HE: hematoxylin and eosin; FASN: fatty acid synthase; ATGL: adipose triglyceride lipase; HSL: hormone sensitive lipase.

Fig. 4. Inflammatory responses of EWAT in diabetic mice. (A) Immunohistochemical staining showing accumulation of T-bet ${ }^{+}$(Th1), ROR- $\gamma \mathrm{t}^{+}$(Th17) and Foxp3 $3^{+}$(Treg) cells in EWAT (brown staining considered positive staining; scale bar: $50 \mu \mathrm{m}$ ). (B) Semi-quantification of T-bet (Th1), ROR- $\gamma$ t (Th17)and Foxp3 (Treg) immunohistochemical staining in EWAT. (C) Immunohistochemical staining showing accumulation of $\mathrm{CD}_{11 \mathrm{c}^{+}}$(M1), $\mathrm{CD}^{206}{ }^{+}$(M2) and F4/80+ cells in EWAT (brown staining considered positive staining; scale

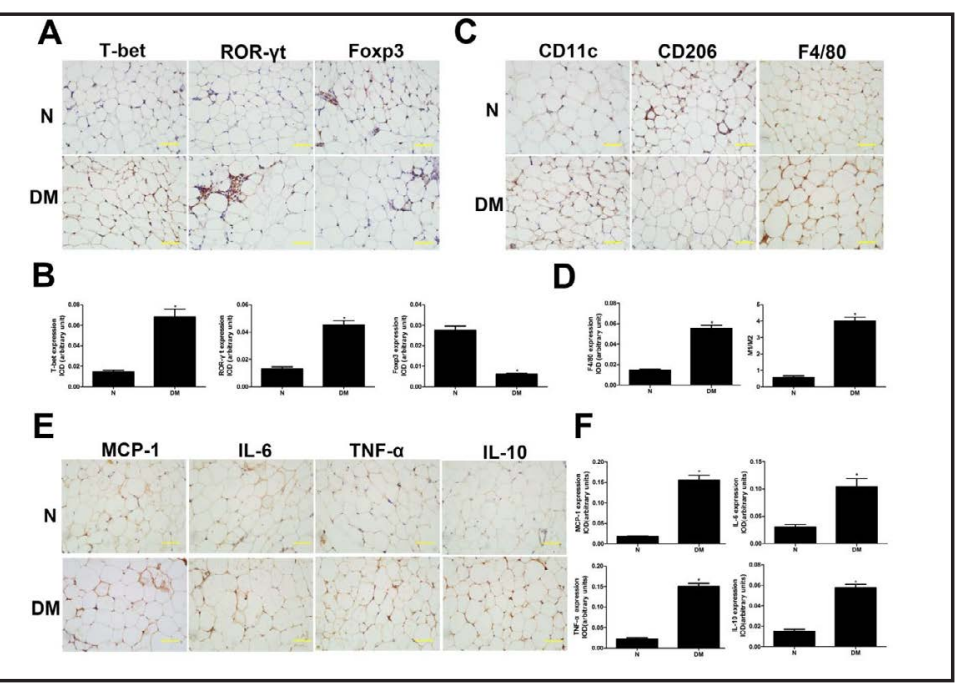
bar: $50 \mu \mathrm{m}$ ). (D) Semi-quantification of F4/80 immunnohistochemical staining and analysis of the ratio of $\mathrm{CD}_{11 \mathrm{c}^{+}}$(M1) cells to CD206+ (M2) cells in EWAT. (E) Immunohistochemical staining for MCP-1, IL-6, TNF- $\alpha$ and IL-10 in EWAT (brown staining considered positive staining; scale bar: $50 \mu \mathrm{m}$ ). (F) Semi-quantification of MCP-1, IL-6, TNF- $\alpha$ and IL-10 immunohistochemical staining in EWAT. Data are mean \pm SEM ( $n=7-8$ per group). ${ }^{*} \mathrm{P}<0.05$ verus N. IOD: integrated optical density; EWAT: epididymal white adipose tissue; Th1: T-helper 1 cells; Th17: T-helper 17 cells; Treg: T-regulatory cells; MCP-1: Monocyte Chemoattractant Protein-1; IL-6: Interleukin-6; TNF- $\alpha$ : Tumor Necrosis Factor- $\alpha$; IL-10: Interleukin-10. 
Fig. 5. PTPN2 overexpression in EWAT ameliorates adipose tissue morphological and functional remodeling. (A) Immunohistochemical staining showing accumulation of PTPN2-positive cells in EWAT (brown staining considered positive staining; scale bar: $50 \mu \mathrm{m}$ ). (B) Representative Western blot of PTPN2 protein expression in EWAT. (C) The weight of EWAT. (D) EWAT stained with HE (Scale bars: $50 \mu \mathrm{m}$ ). (E) Immunohistochemical staining for FASN, ATGL, HSL and Perilipin in EWAT (brown staining considered positive staining; scale bar: $50 \mu \mathrm{m}$ ). (F) Semi-quantification of Fasn, ATGL, HSL and Perilipin immunohistochemical staining in EWAT. Data are mean \pm SEM ( $\mathrm{n}=7-8$ per group). ${ }^{*} \mathrm{P}<0.05$

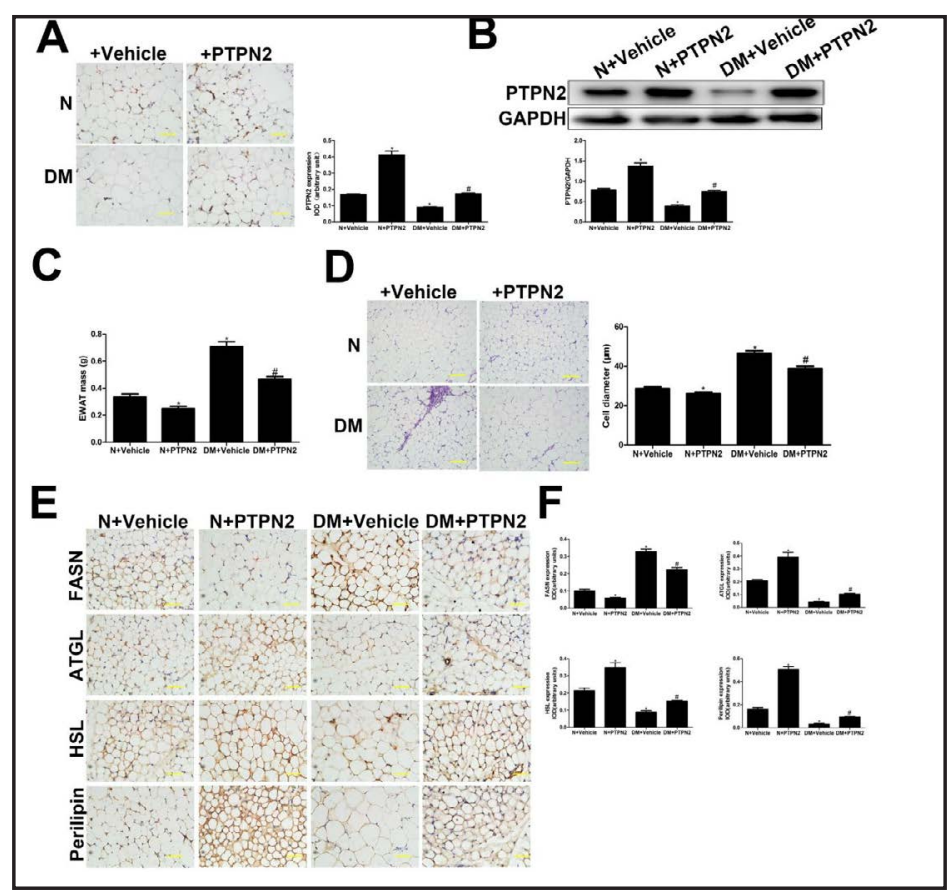
verus $\mathrm{N}+$ Vehicle; ${ }^{\#} \mathrm{P}<0.05$ verus DM+Vehicle. IOD: integrated optical density; EWAT: epididymal white adipose tissue; HE: hematoxylin and eosin; FASN: fatty acid synthase; ATGL: adipose triglyceride lipase; HSL: hormone sensitive lipase.

Fig. 6. PTPN2 overexpression in EWAT regulates adipose tissue Th1/ Treg and Th17/Treg balance. (A) Representative Western blot of T-bet (Th1), ROR- $\gamma$ t (Th17) and Foxp3 (Treg) protein expression in EWAT. (B) Immunohistochemical staining showing accumulation of T-bet ${ }^{+}$(Th1), ROR- $\gamma \mathrm{t}^{+}$(Th17) and Foxp3 ${ }^{+}$(Treg) cells in EWAT (brown staining considered positive staining; scale bar: $50 \mu \mathrm{m}$ ); (C) Flow cytometry analysis of IFN- $\gamma^{+}$ Th1 in EWAT. (D) Flow cytometry analysis of IL-17+ Th17 in EWAT. (E) Flow cytometry analysis of Foxp3 ${ }^{+}$ Treg in EWAT. Data are mean \pm SEM ( $\mathrm{n}=7-8$ per group). ${ }^{*} \mathrm{P}<0.05$ verus $\mathrm{N}+$ Vehicle; ${ }^{*} \mathrm{P}<0.05$ verus $\mathrm{DM}+$ Vehicle. IOD: integrated optical density; EWAT: epididymal white adipose tissue; Th1: T-helper 1 cells; Th17: T-helper 17

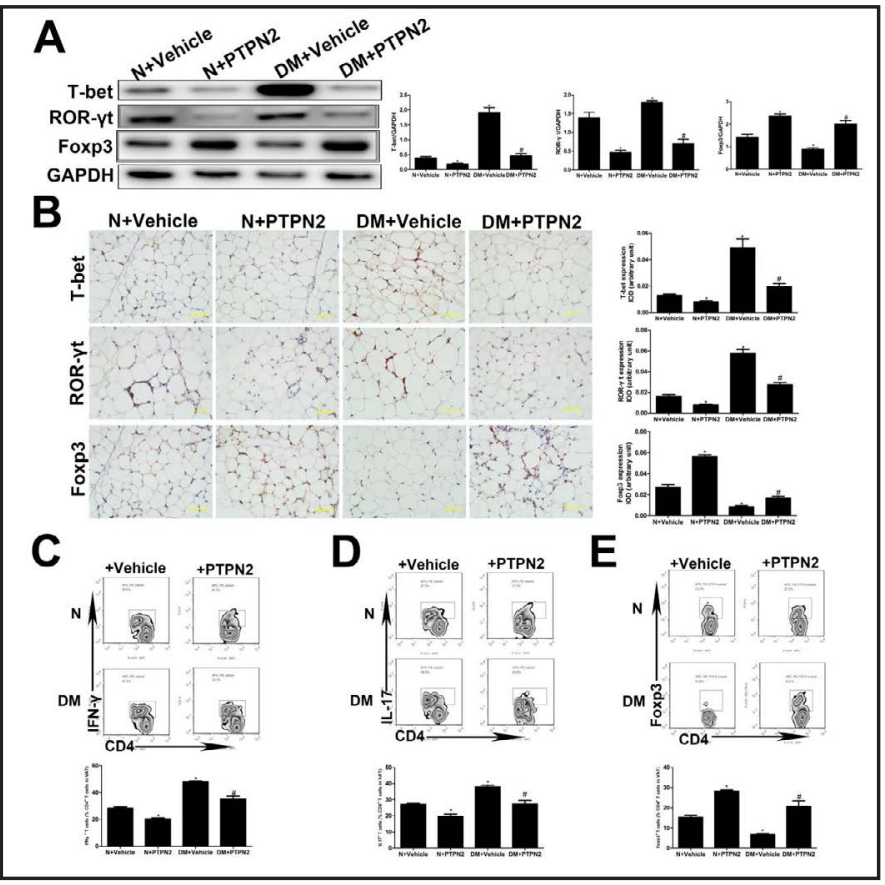
cells; Treg: T-regulatory cells.

\section{Inflammatory responses of EWAT in diabetic mice}

Our data revealed T-bet ${ }^{+}$cells (Th1 cells) and ROR- $\gamma \mathrm{t}^{+}$cells (Th17 cells) were detected both in normal and diabetic EWAT, but at significantly higher numbers in diabetic EWAT $(P<0.05)$ (Fig. 4A-B). Yet, the number of Foxp3 ${ }^{+}$cells (Treg) was significantly decreased in diabetic EWAT $(P<0.05)$ (Fig. 4A-B). 
Fig. 7. PTPN2 overexpression in EWAT reduces adipose tissue macrophages infiltration and the ratio of M1/M2 macrophages. (A) Immunohistochemical staining showing accumulation of $\mathrm{F} 4 / 80^{+}, \mathrm{CD}_{11 \mathrm{c}^{+}}$(M1) and $\mathrm{CD}_{206}{ }^{+}$(M2) cells in EWAT (brown staining considered positive staining; scale bar: 50 $\mu \mathrm{m}$ ); (B) Semi-quantification of F4/80 immunnohistochemical staining and analysis of the ratio of $\mathrm{CD}_{11 \mathrm{c}^{+}}$(M1) cells to CD206 ${ }^{+}$ (M2) cells in EWAT; (C) Repre-
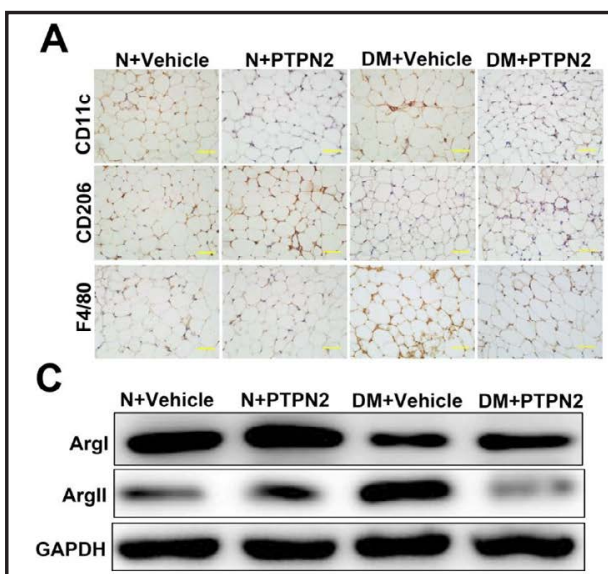
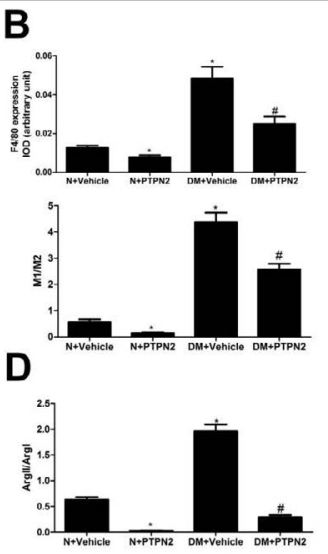
sentative Western blot of Arg II

(M1) and Arg I (M2) protein expression in EWAT. (D) Western blot analysis of Arg II/Arg I in EWAT. Data are mean \pm SEM ( $n=7-8$ per group). ${ }^{*} \mathrm{P}<0.05$ verus $\mathrm{N}+$ Vehicle; ${ }^{\#} \mathrm{P}<0.05$ verus $\mathrm{DM}+$ Vehicle. IOD: integrated optical density; EWAT: epididymal white adipose tissue; Arg II: Arginase II; Arg I: Arginase I.

Fig. 8. PTPN2 overexpression in EWAT significantly suppresses adipose tissue inflammation, reduces system inflammation and improves insulin resistance. (A) Immunohistochemical staining for MCP-1, IL-6, TNF- $\alpha$ and IL-10 in EWAT (brown staining considered positive staining; scale bar: $50 \mu \mathrm{m})$. (B) Semi-quantification of MCP-1, IL-6, TNF- $\alpha$ and IL-10 immunohistochemical staining in EWAT. (C) Representative Western blot of MCP-1, IL6, TNF- $\alpha$ and IL-10 in EWAT. (D) Western blot analysis of MCP-1, IL-6, TNF- $\alpha$ and IL10 in EWAT. (E) Circulating levels of IL-6, IFN- $\gamma$, TNF- $\alpha$, MCP-1 and CRP. (F) Glucose tolerance tests and the area under blood glucose concen-

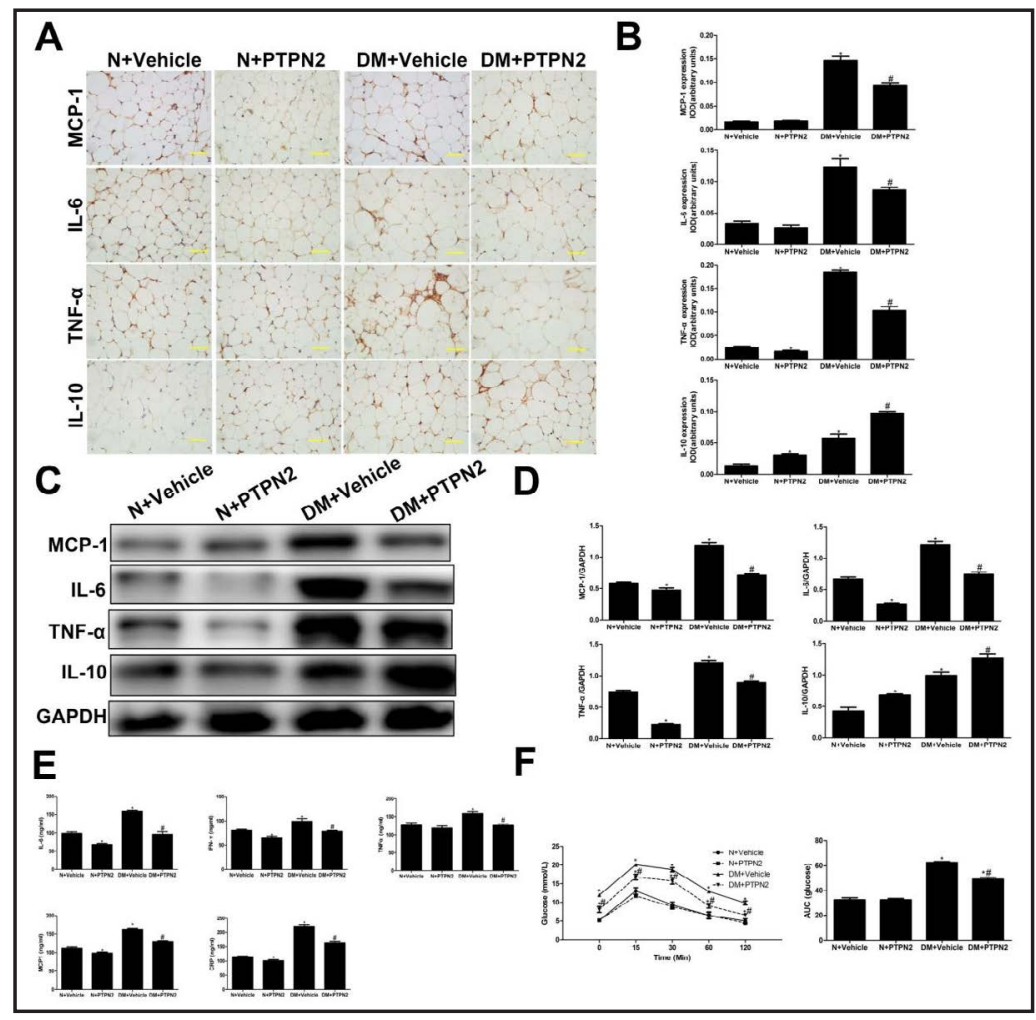
tration curve (AUC) at the age of 24 weeks. Data are mean \pm SEM $\left(n=7-8\right.$ per group). ${ }^{*} \mathrm{P}<0.05$ verus $\mathrm{N}+$ Vehicle; ${ }^{\#} \mathrm{P}<0.05$ verus $\mathrm{DM}+$ Vehicle. IOD: integrated optical density; EWAT: epididymal white adipose tissue; MCP-1: Monocyte Chemoattractant Protein-1; IL-6: Interleukin-6; IL-10: Interleukin-10; IFN- $\gamma$ : Interferon- $\gamma$; TNF- $\alpha$ : Tumor Necrosis Factor- $\alpha$; CRP: C-Reactive Protein.

The number of infiltrating macrophages in EWAT was significantly increased in the diabetic group than normal group $(P<0.05)$ (Fig. 4C-D). The numbers of M1 and M2 macrophages using CD11c and CD206 as M1 and M2 markers respectively were significantly increased in EWAT in the diabetic group. The ratio of M1/M2 macrophages was elevated in 
EWAT in the diabetic group $(P<0.05)$ (Fig. 4C-D).

We also investigated the expression of inflammatory cytokines in EWAT. The MCP-1, IL-6 and TNF- $\alpha$, pro-inflammatory cytokines secreted by M1 macrophages, were upregulated in EWAT in diabetic $\mathrm{ApoE}^{-/}$mice compared with those in normal group $(P<0.05)$ (Fig. 4E-F). The IL10, anti-inflammatory cytokine produced by M2 macrophages, was also upregulated in EWAT in diabetic $\mathrm{ApoE}^{-/-}$mice $(P<0.05)$ (Fig. 4E-F). Our results suggested that diabetes induced proinflammatory factors and promoted $\mathrm{T}$ cells proinflammatory polarization in EWAT in $\mathrm{ApoE}^{-/-}$mice.

\section{PTPN2 overexpression in EWAT ameliorated adipose tissue morphological and functional remodeling}

Compared with the $\mathrm{N}+$ Vehicle group, the protein level of PTPN2 was significantly decreased in EWAT in the DM+Vehicle group, as assessed by immunohistochemistry and Western blot analysis $(P<0.05)$ (Fig. 5A-B). With PTPN2 overexpression in EWAT, the PTPN2 protein level was significantly increased in the DM+PTPN2 group compared with the DM+Vehicle group $(P<0.05)$ (Fig. 5A-B).

After treatment, the EWAT mass was significantly decreased in DM+PTPN2 group compared with the $\mathrm{DM}+$ Vehicle group $(P<0.05)$

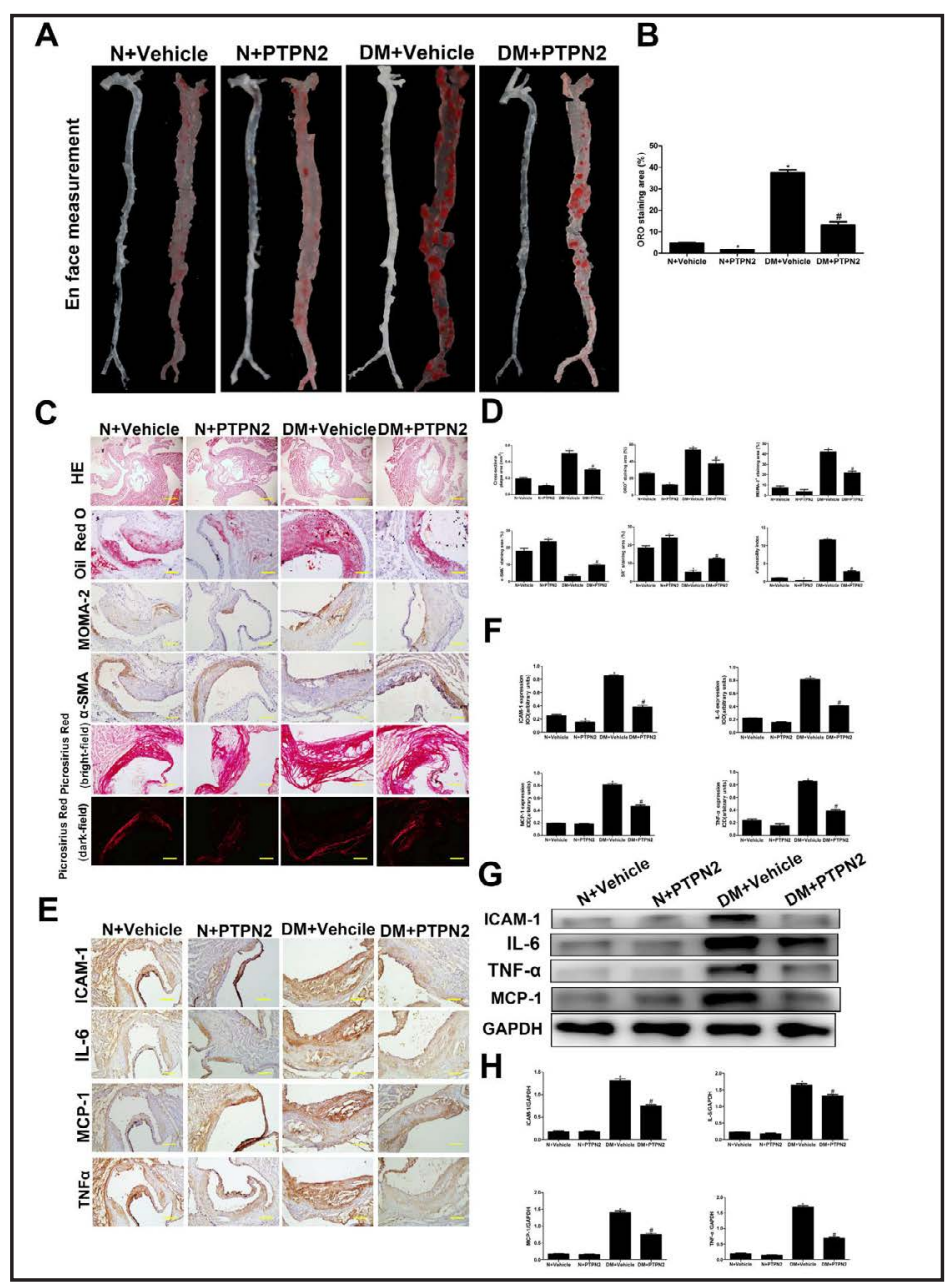

Fig. 9. PTPN2 overexpression in EWAT inhibits atherosclerosis inflammation and increases the plaque stability. (A) Representative en face view of aortic tree stained with Oil Red O. (B) Quantitative analysis of en face aorta lesions expressed as percentage lesion area relative to total aorta area. (C) Representative photomicrographs of aortic root sections stained with HE (scale bar: $200 \mu \mathrm{m}$ ), Oil-Red O staining (scale bar: $50 \mu \mathrm{m}$ ), MOMA-2 (scale bar: $50 \mu \mathrm{m}$ ), $\alpha$-SMA (scale bar: $50 \mu \mathrm{m}$ ) immunohistochemical staining and picrosirius red staining (scale bar: $50 \mu \mathrm{m}$ ). (D) Quantification of cross-sectional plaque area, plaque lipid deposition, macrophage content, plaque smooth muscle cell content, collagen content and vulnerability index in aortic root sections. (E) Representative images of ICAM-1, IL-6, TNF- $\alpha$ and MCP-1 immunohistochemical staining in aortic root sections. (F) Semi-quantification of ICAM-1, IL-6, TNF- $\alpha$ and MCP-1 immunohistochemical staining in aortic root sections. (G) Representative Western blot of ICAM-1, IL-6, TNF- $\alpha$ and MCP-1 protein expression in mouse aorta. $(\mathrm{H})$ Western blot analysis of ICAM-1, IL-6, TNF- $\alpha$ and MCP-1 in mouse aorta. Data are mean \pm SEM ( $\mathrm{n}=7-8$ per group). ${ }^{*} \mathrm{P}<0.05$ verus $\mathrm{N}+$ Vehicle; ${ }^{*} \mathrm{P}<0.05$ verus DM+Vehicle. IOD: integrated optical density; EWAT: epididymal white adipose tissue; MOMA-2: Monocyte/Macrophage Marker; $\alpha$-SMA: $\alpha$-Smooth muscle actin; ICAM-1: Intercellular Cell Adhesion Molecule-1; IL-6: Interleukin-6; TNF- $\alpha$ : Tumor Necrosis Factor- $\alpha$; MCP-1: Monocyte Chemoattractant Protein-1.

\section{KARGER}




\section{Cellular Physiology Cell Physiol Biochem 2018;46:118-132 \\ \begin{tabular}{l|l} 
DOI: 10.1159/000488415 & O 2018 The Author(s). Published by S. Karger AG, Basel \\
and Biochemistry Published online: March 26, 2018 & \begin{tabular}{l} 
www.karger.com/cpb \\
\cline { 2 - 4 }
\end{tabular}
\end{tabular} \\ Li et al.: PTPN2 Overexpression in Visceral Adipose Tissue Ameliorated Atherosclerosis}

(Fig. 5C). HE staining of EWAT revealed significant decreases in adipocyte cell size in DM+PTPN2 group compared with the DM+Vehicle group $(P<0.05)$ (Fig. 5D).

We next evaluated the potential impact of PTPN2 on EWAT fatty acid metabolism by immunohistochemistry. We found decreased Fasn and increased ATGL, HSL, and Perilipin in EWAT of the DM+PTPN2 group compared with the DM+Vehicle group $(P<0.05)$ (Fig. 5E-F). Taken together, these data indicated improvements in both morphological remodeling and metabolic dysfunction in EWAT of the DM+PTPN2 group.

PTPN2 overexpression in EWAT regulated adipose tissue Th1/Treg and Th17/Treg balance

To characterize the polarization of $\mathrm{T}$ cells in EWAT of diabetic mice, expression levels of T cells markers (T-bet, ROR- $\gamma$ t and Foxp3) were analyzed to distinguish between pro-inflammatory Th1 and Th17 phenotypes and anti-inflammatory Treg phenotypes, respectively. T-bet ${ }^{+}$(Th1) cells and ROR- $\gamma \mathrm{t}^{+}$(Th17) cells were significantly reduced and Foxp $^{+}$(Treg) cells were significantly restored in the DM+PTPN2 group compared with the DM+Vehicle group $(P<0.05)$ (Fig. 6A-B). Flow cytometric analysis of T-cell subsets in EWAT showed decreased Th1 and Th17 cells and increased Treg cells in the DM+PTPN2 group compared with the DM+Vehicle group $(P<0.05)$ (Fig. 6C-E). Considered together, these findings suggested that PTPN2 promoted Treg while reducing Th1 and Th17 in EWAT of diabetic mice, and that PTPN2 overexpression in EWAT reversed the high Th1/Treg and Th17/Treg ratios in diabetic mice.

PTPN2 overexpression in EWAT reduced adipose tissue macrophages infiltration and the ratio of M1/M2 macrophages

Recent studies have demonstrated that T-cell-mediated inflammation affects adipose tissue macrophage (ATMs) function, thereby contributing to adipose tissue inflammation and insulin resistance $[15,16,34]$. We examined whether PTPN2 overexpression in EWAT affects ATMs in diabetic mice. ATMs accumulation in EWAT was reduced as detected by immunostaining, with reduced crown-like structures in the DM+PTPN2 group compared with the DM+Vehicle group $(P<0.05)$ (Fig. 7A-B). In addition, DM+PTPN2 group showed significantly decreased M1/M2 macrophages ratio in EWAT $(P<0.05)$ (Fig. 7A-B).

To further characterize the polarization of macrophages in EWAT of diabetic mice, expression levels of arginase isoforms (ArgII and ArgI) were analyzed to distinguish between pro-inflammatory M1 and anti-inflammatory M2 phenotypes, respectively. Both macrophage phenotypes are present in diabetic EWAT, ArgII (M1) being the most abundantly expressed in the DM+Vehicle group and ArgI (M2) the predominant macrophage marker in the DM+PTPN2 group (Fig. 7C-D). These data suggested that PTPN2 overexpression in EWAT reduced ATMs infiltration and restored an M2 phenotype in diabetic EWAT.

PTPN2 overexpression in EWAT significantly suppressed adipose tissue inflammation, reduced system inflammation and improved insulin resistance

To evaluate the potential impact of PTPN2 on EWAT inflammation, we assessed protein levels of various markers of inflammation by immunochemistry and western blot. Expression levels of genes implicated in EWAT inflammation, including MCP-1, IL- 6 and IFN- $\gamma$, were reduced in DM+PTPN2 group compared with the DM+Vehicle group (Fig. 8A-D). The antiinflammatory cytokine IL-10 was upregulated in EWAT in DM+PTPN2 group compared with the DM+Vehicle group (Fig. 8A-D).

We next investigated whether the DM+PTPN2 group and the DM+Vehicle group differed in systemic inflammatory status, a hallmark of both diabetes and atherosclerosis. Consistent with the above gene expression in EWAT, the circulating levels of MCP-1, TNF- $\alpha$, IL-6, IFN- $\gamma$ and C-Reactive protein (CRP) were significantly decreased respectively in the DM+PTPN2 group (Fig. 8E). Compared with the DM+Vehicle group, DM+PTPN2 group showed significantly lower blood glucose levels and mean AUC on IPGTT (Fig. 8F). These data suggested that PTPN2 overexpression in EWAT limited local and system inflammation and improved insulin resistance in diabetic $\mathrm{ApoE}^{-/-}$mice. 
PTPN2 overexpression in EWAT inhibited atherosclerosis inflammation and increased the plaque stability

We investigated whether a dampened inflammatory response in EWAT in atherogenic mice had any effect on atherosclerosis development. Oil Red $\mathrm{O}$ en face staining showed a marked reduction in atherosclerotic plaque formation along the aortic tree in the DM+PTPN2 group compared to the DM+Vehicle group $(P<0.05)$ (Fig. 9A-B), as well as at the aortic root of the DM+PTPN2 group $(P<0.05)$ (Fig. 9C). There was less macrophage accumulation as reflected

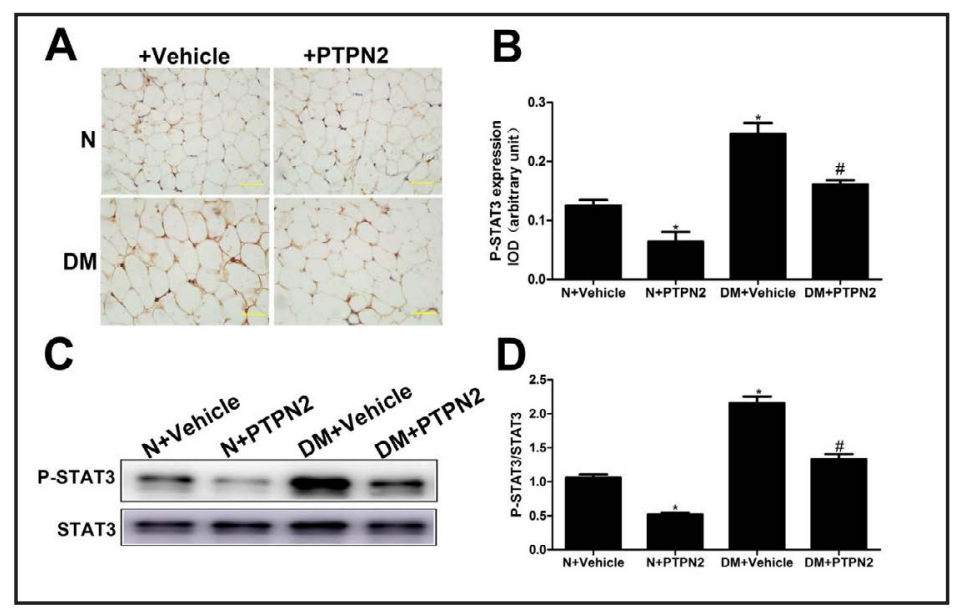

Fig. 10. In EWAT, STAT3 pathway is activated in diabetes states; while PTPN2 overexpression in EWAT reverses adipose tissue STAT3 pathway activation. (A) Immunohistochemical staining showing accumulation of P-STAT3-positive cells in EWAT (brown staining considered positive staining; scale bar: $50 \mu \mathrm{m}$ ). (B) Semi-quantification of P-STAT3 immunnohistochemical staining in EWAT; (C) Representative Western blot of P-STAT3 and STAT3 protein expression in EWAT. (D) Western blot analysis of P-STAT3/STAT3 in EWAT. Data are mean \pm SEM (n=7-8 per group). ${ }^{*} \mathrm{P}<0.05$ verus $\mathrm{N}+$ Vehicle; ${ }^{*} \mathrm{P}<0.05$ verus $\mathrm{DM}+$ Vehicle. IOD: integrated optical density; EWAT: epididymal white adipose tissue.

by MOMA-2 staining, and more vascular smooth muscle cells as reflected by $\alpha$-SMA staining $(P<0.05)$ (Fig. 9C). Collagen content in the atherosclerotic plaques at the aortic root in the DM+PTPN2 group was also increased compared to the DM+Vehicle group $(P<0.05)$ (Fig. 9C-D). Consequently, the plaque vulnerability index was dramatically decreased after PTPN2 overexpression in EWAT $(P<0.05)$ (Fig. 9C-D). In line with these histology results, the gene expression of ICAM-1, IL-6, MCP- 1 and TNF- $\alpha$, were significantly down-regulated in aorta from the DM+PTPN2 group $(P<0.05)($ Fig. 9E-H). Thus, PTPN2 overexpression in EWAT could suppress atherosclerosis inflammation and change the composition of plaques to a more stabilized phenotype.

\section{PTPN2 overexpression in EWAT inhibited STAT3 pathway}

It was known previously that PTPN2 regulates STAT3 signaling pathway [35] and STAT3 pathway is known to promote the differentiation of pro-inflammatory IFN- $\gamma$-producing Th1 cells and IL-17-producing Th17 cells while inhibiting anti-inflammatory Foxp $3^{+}$regulatory T cells (Treg) [15]. Thus, we investigated whether PTPN2 modulate T cells polarization via STAT3 signaling pathway in EWAT.

We have shown that the PTPN2 protein level in EWAT was significantly decreased in the $\mathrm{DM}+$ Vehicle group compared with the N+Vehicle group (Fig. 5A-B). This appears to cause the up-regulation of STAT3 activity in EWAT. Phosphorylation of STAT3, the measure of STAT3 activation, was increased in the DM+Vehicle group by $51 \%$ compared with the N+Vehicle group in EWAT $(P<0.05)$ (Fig. 10A-D). PTPN2 overexpression significantly decreased the EWAT P-STAT3 level by 38\% in the DM+PTPN2 group compared with the DM+Vehicle group $(P<0.05)$ (Fig. 10A-D).

These results suggested that the PTPN2 reduced the pathogenesis of atherosclerosis by abolishing the STAT3 signalling pathway and preventing T cells pro-inflammatory polarization in EWAT of diabetic mice. 


\section{Cellular Physiology and Biochemistry

\section{Discussion}

In this study of diabetic ApoE ${ }^{-/}$mice, we found that with decreased expression of PTPN2 in VAT, T cells in VAT adopted a pro-inflammatory polarization, which induced local and systemic inflammation and promoted atherosclerotic plaque vulnerability; PTPN2 overexpression in VAT could significantly reduce the ratios of Th1/Treg and Th17/Treg, inhibit local and systemic inflammation, and thus stabilize atherosclerotic plaque; mechanistically, PTPN2 was found to inhibit the STAT3 signaling pathway to involve in adipose tissue T cells polarization, inflammation and subsequently caused alleviation of diabetic atherosclerosis progression.

VAT remodeling has been suggested to be the major contributor for systemic inflammation and accelerate atherogenesis [36]. Our data demonstrated that diabetes contributed to VAT remodeling, including adipocyte hypertrophy and increased inflammatory factors. Increased fat cell size may represent the failure of the adipose tissue mass to expand and therefore to accommodate an increased energy influx [37]. However, as the fat cells expand, more secretions of inflammatory factors were following, such as MCP-1, IL- 6 and TNF- $\alpha$ in our study about diabetic ApoE $/ /$ mice. TNF- $\alpha$ could inhibit adipogenesis [38] and the inability for adipogenesis may promote adipocyte hypertrophy and aggravate insulin resistance, thus perpetuating a vicious circle $[39,40]$. Furthermore, systemic inflammation originating from the inflamed VAT could promote atherogenesis $[4,6]$. Our results confirmed that diabetes could induce VAT remodeling and inflammation and thus promote atherosclerotic plaque vulnerability. Therefore, decreasing adipose tissue inflammation level and shrinking white fat cell size may be crucial for improving adipose tissue remodeling and atherosclerosis.

Immune dysfunction contribute to adipose tissue inflammation [15] and T cells activation is a primary event in the initiation of adipose tissue inflammation [13]. Our data showed $\mathrm{CD}^{+}{ }^{+} \mathrm{T}$ cells infiltrate VAT, with increased pro-inflammatory Th1 and Th17 and decreased anti-inflammatory Treg in diabetic mice. Seminal studies have demonstrated that both Th1 and Th17 in obese adipose tissue produce pro-inflammatory cytokines such as IL- 6 and TNF- $\alpha$, which drives macrophage pro-inflammatory polarization and exacerbates adipose tissue inflammation $[9,15,41]$, while Treg drive M2 macrophages responses through secreting anti-inflammatory cytokines such as IL-10 and participate in several diverse activities aimed at suppressing inflammation [42]. Thus, it is conceivable that localized $\mathrm{T}$ cell activation in adipose tissue is a primary event, which results in macrophage recruitment and activation and these cells play an important role in the initiation and perpetuation of adipose tissue inflammation. Meanwhile, our results showed that $\mathrm{CD} 4^{+} \mathrm{T}$ cells in diabetic VAT adopted a pro-inflammatory phenotype which induced M1 macrophage phenotype and promoted atherosclerotic plaque vulnerability. However, the underlying mechanism of $\mathrm{T}$ cells polarization during diabetes remains unknown.

PTPN2 might be the key regulator that controls the T cells polarization $[22,23]$. Spalinger et al. reported that loss of PTPN2 in the T-cell compartment caused enhanced induction of Th1 and Th17 cells, but impaired induction of Treg in several mouse colitis models [22]. We found the expression of PTPN2 was significantly decreased in diabetic EWAT. Chronic reactive oxygen species (ROS) generation and oxidative stress occur in diabetes. PTPN2 is an important target for ROS [43]. Thus, ROS may inhibit PTPN2 expression and prevent substrate-binding. Our data showed that PTPN2 gene overexpression in EWAT reversed the high Th1/Treg and Th17/Treg ratios in EWAT of diabetic mice. The ratio of M1/M2 macrophages and the expression of pro-inflammatory cytokines were significantly decreased. Meanwhile, PTPN2 gene overexpression in EWAT attenuated both systemic inflammation and atherogenesis. Therefore, our study demonstrated adenovirus-mediated PTPN2 gene transfer into EWAT could inhibit systemic inflammation and atherosclerosis by modulating the T cells polarization. However, the downstream mediator of PTPN2 in modulating T cells polarization during diabetes remains unknown.

STAT3 signaling pathway is an important downstream mediator of PTPN2 [27] and plays a crucial role in the regulation of T cells polarization [15]. Functional ablation of Stat3 


\section{Cellular Physiology

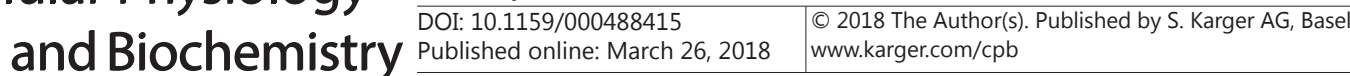 \\ Li et al.: PTPN2 Overexpression in Visceral Adipose Tissue Ameliorated Atherosclerosis}

reverses the high Th1/Treg ratio in VAT of obesity mice [15]. In our study, the ratio of P-STAT3/ STAT3 was increased in EWAT in diabetic ApoE $\%$ mice. With PTPN2 overexpression, the ratios of P-STAT3/STAT3 in EWAT were significantly decreased. Therefore, we proposed that activation of PTPN2 may regulate T cells polarization via inhibiting STAT3 signaling pathway to reduce the expression of pro-inflammatory cytokines, and thus increase atherosclerosis stability.

In summary, we demonstrated that PTPN2 overexpression in EWAT would inhibit systemic inflammation and increase the plaque stability via $\mathrm{T}$ cells polarization shift in diabetic mice.

\section{Conclusion}

Taken together, our findings suggest a crucial role for $\mathrm{T}$ cells polarization in driving VAT inflammation and contributing atherosclerosis. PTPN2 overexpression could significantly reverse the high Th1/Treg and Th17/Treg ratios, inhibit systemic inflammation and thus stabilize plaques in diabetic mice. Consequently, these findings highlight the importance of PTPN2/STAT3 signaling pathway as a potential therapeutic target for blunting adipose tissue inflammation and atherosclerosis.

\section{Acknowledgements}

This work was supported by the National Natural Science Foundation of China (81570400, 81470560, 81400285, 81270352, 81471036, 81600633 and 81670411), the Natural Science Foundation of Shandong Province (BS2011YY024, ZR2014HQ037), and Key research and development program of Shandong Province (2015GSF118062).

\section{Disclosure Statement}

The authors declare that there is no duality of interest associated with this manuscript.

\section{References}

1 Rawshani A, Rawshani A, Franzen S, Eliasson B, Svensson AM, Miftaraj M, McGuire DK, Sattar N, Rosengren A, Gudbjornsdottir S: Mortality and Cardiovascular Disease in Type 1 and Type 2 Diabetes. N Engl J Med 2017;376:1407-1418.

-2 Ridker PM, Danielson E, Fonseca FA, Genest J, Gotto AM, Jr., Kastelein JJ, Koenig W, Libby P, Lorenzatti AJ, Macfadyen JG, Nordestgaard BG, Shepherd J, Willerson JT, Glynn RJ: Reduction in C-reactive protein and LDL cholesterol and cardiovascular event rates after initiation of rosuvastatin: a prospective study of the JUPITER trial. Lancet 2009;373:1175-1182.

-3 Mirza S, Hossain M, Mathews C, Martinez P, Pino P, Gay JL, Rentfro A, McCormick JB, Fisher-Hoch SP: Type 2-diabetes is associated with elevated levels of TNF-alpha, IL-6 and adiponectin and low levels of leptin in a population of Mexican Americans: a cross-sectional study. Cytokine 2012;57:136-142.

-4 Kwok KH, Cheng KK, Hoo RL, Ye D, Xu A, Lam KS: Adipose-specific inactivation of JNK alleviates atherosclerosis in apoE-deficient mice. Clin Sci (Lond) 2016;130:2087-2100.

5 Hamdy 0, Porramatikul S, Al-Ozairi E: Metabolic obesity: the paradox between visceral and subcutaneous fat. Curr Diabetes Rev 2006;2:367-373.

-6 Ohman MK, Shen Y, Obimba CI, Wright AP, Warnock M, Lawrence DA, Eitzman DT: Visceral adipose tissue inflammation accelerates atherosclerosis in apolipoprotein E-deficient mice. Circulation 2008;117:798805. 


\section{Cellular Physiology Cell Physiol Biochem 2018;46:118-132 \begin{tabular}{l|l} 
DOI: 10.1159/000488415 & C 2018 The Author(s). Published by S. Karger AG, Basel \\
www.karger.com/cpb
\end{tabular}

7 Kohlgruber A, Lynch L: Adipose tissue inflammation in the pathogenesis of type 2 diabetes. Curr Diab Rep 2015;15:92.

8 Cipolletta D, Kolodin D, Benoist C, Mathis D: Tissular T(regs): a unique population of adipose-tissueresident Foxp3+CD4+ T cells that impacts organismal metabolism. Semin Immunol 2011;23:431-437.

-9 Sell H, Habich C, Eckel J: Adaptive immunity in obesity and insulin resistance. Nat Rev Endocrinol 2012;8:709-716.

10 Winer S, Winer DA: The adaptive immune system as a fundamental regulator of adipose tissue inflammation and insulin resistance. Immunol Cell Biol 2012;90:755-762.

11 Han L, Tang MX, Ti Y, Wang ZH, Wang J, Ding WY, Wang H, Zhang Y, Zhang W, Zhong M: Overexpressing STAMP2 improves insulin resistance in diabetic ApoE(-)/(-)/LDLR(-)/(-) mice via macrophage polarization shift in adipose tissues. PLoS One 2013;8:e78903.

12 Hirata Y, Tabata M, Kurobe H, Motoki T, Akaike M, Nishio C, Higashida M, Mikasa H, Nakaya Y, Takanashi S, Igarashi T, Kitagawa T, Sata M: Coronary atherosclerosis is associated with macrophage polarization in epicardial adipose tissue. J Am Coll Cardiol 2011;58:248-255.

13 Kintscher U, Hartge M, Hess K, Foryst-Ludwig A, Clemenz M, Wabitsch M, Fischer-Posovszky P, Barth TF, Dragun D, Skurk T, Hauner H, Bluher M, Unger T, Wolf AM, Knippschild U, Hombach V, Marx N: T-lymphocyte infiltration in visceral adipose tissue: a primary event in adipose tissue inflammation and the development of obesity-mediated insulin resistance. Arterioscler Thromb Vasc Biol 2008;28:1304-1310.

14 Harford KA, Reynolds CM, McGillicuddy FC, Roche HM: Fats, inflammation and insulin resistance: insights to the role of macrophage and T-cell accumulation in adipose tissue. Proc Nutr Soc 2011;70:408-417.

-15 Priceman SJ, Kujawski M, Shen S, Cherryholmes GA, Lee H, Zhang C, Kruper L, Mortimer J, Jove R, Riggs AD, Yu H: Regulation of adipose tissue T cell subsets by Stat3 is crucial for diet-induced obesity and insulin resistance. Proc Natl Acad Sci U S A 2013;110:13079-13084.

-16 Winer S, Chan Y, Paltser G, Truong D, Tsui H, Bahrami J, Dorfman R, Wang Y, Zielenski J, Mastronardi F, Maezawa Y, Drucker DJ, Engleman E, Winer D, Dosch HM: Normalization of obesity-associated insulin resistance through immunotherapy. Nat Med 2009;15:921-929.

17 Nishimura S, Manabe I, Nagasaki M, Eto K, Yamashita H, Ohsugi M, Otsu M, Hara K, Ueki K, Sugiura S, Yoshimura K, Kadowaki T, Nagai R: CD8+ effector T cells contribute to macrophage recruitment and adipose tissue inflammation in obesity. Nat Med 2009;15:914-920.

18 Tiemessen MM, Jagger AL, Evans HG, van Herwijnen MJ, John S, Taams LS: CD4+CD25+Foxp3+ regulatory T cells induce alternative activation of human monocytes/macrophages. Proc Natl Acad Sci U S A 2007;104:19446-19451.

19 Hong EG, Ko HJ, Cho YR, Kim HJ, Ma Z, Yu TY, Friedline RH, Kurt-Jones E, Finberg R, Fischer MA, Granger EL, Norbury CC, Hauschka SD, Philbrick WM, Lee CG, Elias JA, Kim JK: Interleukin-10 prevents dietinduced insulin resistance by attenuating macrophage and cytokine response in skeletal muscle. Diabetes 2009;58:2525-2535.

20 Park-Min KH, Antoniv TT, Ivashkiv LB: Regulation of macrophage phenotype by long-term exposure to IL10. Immunobiology 2005;210:77-86.

-21 Feuerer M, Herrero L, Cipolletta D, Naaz A, Wong J, Nayer A, Lee J, Goldfine AB, Benoist C, Shoelson S, Mathis D: Lean, but not obese, fat is enriched for a unique population of regulatory $\mathrm{T}$ cells that affect metabolic parameters. Nat Med 2009;15:930-939.

-22 Spalinger MR, Kasper S, Chassard C, Raselli T, Frey-Wagner I, Gottier C, Lang S, Atrott K, Vavricka SR, Mair F, Becher B, Lacroix C, Fried M, Rogler G, Scharl M: PTPN2 controls differentiation of CD4(+) T cells and limits intestinal inflammation and intestinal dysbiosis. Mucosal Immunol 2015;8:918-929.

23 Wiede F, Shields BJ, Chew SH, Kyparissoudis K, van Vliet C, Galic S, Tremblay ML, Russell SM, Godfrey DI, Tiganis T: T cell protein tyrosine phosphatase attenuates $\mathrm{T}$ cell signaling to maintain tolerance in mice. J Clin Invest 2011;121:4758-4774.

24 Cool DE, Tonks NK, Charbonneau H, Walsh KA, Fischer EH, Krebs EG: cDNA isolated from a human T-cell library encodes a member of the protein-tyrosine-phosphatase family. Proc Natl Acad Sci U S A 1989;86:5257-5261.

25 Doody KM, Bourdeau A, Tremblay ML: T-cell protein tyrosine phosphatase is a key regulator in immune cell signaling: lessons from the knockout mouse model and implications in human disease. Immunol Rev 2009;228:325-341. 


\section{Cellular Physiology Cell Physiol Biochem 2018;46:118-132 \begin{tabular}{l|l|l} 
DOI: 10.1159/000488415 & Cond Biochemistry 2018 The Author(s). Published by S. Karger AG, Basel \\
wwww.karger.com/cpb
\end{tabular}

-26 Ren F, Geng Y, Minami T, Qiu Y, Feng Y, Liu C, Zhao J, Wang Y, Fan X, Wang Y, Li M, Li J, Chang Z: Nuclear termination of STAT3 signaling through SIPAR (STAT3-Interacting Protein As a Repressor)-dependent recruitment of T cell tyrosine phosphatase TC-PTP. FEBS Lett 2015;589:1890-1896.

-27 Lee H, Kim M, Baek M, Morales LD, Jang IS, Slaga TJ, DiGiovanni J, Kim DJ: Targeted disruption of TC-PTP in the proliferative compartment augments STAT3 and AKT signaling and skin tumor development. Sci Rep 2017;7:45077.

28 Wang ZH, Shang YY, Zhang S, Zhong M, Wang XP, Deng JT, Pan J, Zhang Y, Zhang W: Silence of TRIB3 suppresses atherosclerosis and stabilizes plaques in diabetic ApoE-/-/LDL receptor-/- mice. Diabetes 2012;61:463-473.

29 Kolodin D, van Panhuys N, Li C, Magnuson AM, Cipolletta D, Miller CM, Wagers A, Germain RN, Benoist C, Mathis D: Antigen- and cytokine-driven accumulation of regulatory T cells in visceral adipose tissue of lean mice. Cell Metab 2015;21:543-557.

-30 Wang J, Han L, Wang ZH, Ding WY, Shang YY, Tang MX, Li WB, Zhang Y, Zhang W, Zhong M: Overexpression of STAMP2 suppresses atherosclerosis and stabilizes plaques in diabetic mice. J Cell Mol Med 2014;18:735748.

-31 Nagamatsu S, Nakamichi Y, Ohara-Imaizumi M, Ozawa S, Katahira H, Watanabe T, Ishida H: Adenovirusmediated preproinsulin gene transfer into adipose tissues ameliorates hyperglycemia in obese diabetic KKA(y) mice. FEBS Lett 2001;509:106-110.

-32 Li Y, Qin R, Yan H, Wang F, Huang S, Zhang Y, Zhong M, Zhang W, Wang Z: Inhibition of vascular smooth muscle cells premature senescence with rutin attenuates and stabilizes diabetic atherosclerosis. J Nutr Biochem 2018;51:91-98.

33 Sun M, Chen M, Dawood F, Zurawska U, Li JY, Parker T, Kassiri Z, Kirshenbaum LA, Arnold M, Khokha R, Liu PP: Tumor necrosis factor-alpha mediates cardiac remodeling and ventricular dysfunction after pressure overload state. Circulation 2007;115:1398-1407.

-34 McLaughlin T, Liu LF, Lamendola C, Shen L, Morton J, Rivas H, Winer D, Tolentino L, Choi O, Zhang H, Hui Yen Chng M, Engleman E: T-cell profile in adipose tissue is associated with insulin resistance and systemic inflammation in humans. Arterioscler Thromb Vasc Biol 2014;34:2637-2643.

-35 Shields BJ, Wiede F, Gurzov EN, Wee K, Hauser C, Zhu HJ, Molloy TJ, O’Toole SA, Daly RJ, Sutherland RL, Mitchell CA, McLean CA, Tiganis T: TCPTP regulates SFK and STAT3 signaling and is lost in triple-negative breast cancers. Mol Cell Biol 2013;33:557-570.

-36 Ouchi N, Parker JL, Lugus JJ, Walsh K: Adipokines in inflammation and metabolic disease. Nat Rev Immunol 2011;11:85-97.

37 Hotamisligil GS, Shargill NS, Spiegelman BM: Adipose expression of tumor necrosis factor-alpha: direct role in obesity-linked insulin resistance. Science 1993;259:87-91.

-38 Hammarstedt A, Isakson P, Gustafson B, Smith U: Wnt-signaling is maintained and adipogenesis inhibited by TNFalpha but not MCP-1 and resistin. Biochem Biophys Res Commun 2007;357:700-706.

-39 Danforth E, Jr.: Failure of adipocyte differentiation causes type II diabetes mellitus? Nat Genet 2000;26:13.

-40 Heilbronn L, Smith SR, Ravussin E: Failure of fat cell proliferation, mitochondrial function and fat oxidation results in ectopic fat storage, insulin resistance and type II diabetes mellitus. Int J Obes Relat Metab Disord 2004;28:S12-21.

41 Liu G, Ma H, Qiu L, Li L, Cao Y, Ma J, Zhao Y: Phenotypic and functional switch of macrophages induced by regulatory CD4+CD25+ T cells in mice. Immunol Cell Biol 2011;89:130-142.

42 Lee BC, Lee J: Cellular and molecular players in adipose tissue inflammation in the development of obesityinduced insulin resistance. Biochim Biophys Acta 2014;1842:446-462.

43 Tiganis T: Reactive oxygen species and insulin resistance: the good, the bad and the ugly. Trends Pharmacol Sci 2011;32:82-89. 